\title{
P I 9-45. Development of a therapeutic HIV vaccine comprised of autologous dendritic cells loaded with a mixture of lipopeptide HIV antigens
}

\author{
AJ Cobb*1, H Mead ${ }^{1}$, M Montes $^{1}$, R Ranganathan ${ }^{1}$, S Burkeholder ${ }^{1}$, J Perry- \\ Finholt ${ }^{1}$, AK Palucka1 ${ }^{1}$ B King ${ }^{2}$, L Sloan ${ }^{2}$, Y Levy ${ }^{3}$, LK Roberts ${ }^{4}$ and \\ $\mathrm{J}_{\text {Banchereau }}{ }^{1}$
}

Address: ${ }^{1}$ Baylor Institute for Immunology Research, Dallas, TX, USA, ${ }^{2}$ North Texas Infectious Disease Clinic, Dallas, TX, USA, ${ }^{3}$ Agence Nationale de Recherche sur le Sida et les hépatites virales, Paris, France and ${ }^{4}$ Roberts Biotech Consulting, LLC, Memphis, TN, USA

* Corresponding author

from AIDS Vaccine 2009

Paris, France. 19-22 October 2009

Published: 22 October 2009

Retrovirology 2009, 6(Suppl 3):P365 doi:10.1 186/1742-4690-6-S3-P365

This abstract is available from: http://www.retrovirology.com/content/6/S3/P365

(c) 2009 Cobb et al; licensee BioMed Central Ltd.

\section{Background}

Clinical trials have shown that dendritic cell (DC)-based vaccines can induce antigen-specific immune responses as well as clinical responses in patients with stage IV cancer. In this study, a monocyte-derived DC vaccine pulsed with HIV antigen lipopeptides (LIPO5) was developed in preparation for a pilot vaccine clinical trial (DALIA) aimed at boosting the cellular immune response in chronic HIV infected patients on highly-active antiretroviral therapy (HAART).

\section{Methods}

Monocytes from six HIV-positive subjects on HAART were cultured with granulocyte macrophage-colony stimulating factor and interferon- $\alpha$, loaded with LIPO5 peptides, and activated with lipopolysaccharide. LIPO5 is composed of five long immunogenic peptides of Gag p17 (17-35), Gag p24 (253-284), Nef (66-97), Nef (116$145)$, and Pol (325-355), which are covalently linked to a palmitoyl-lysylamide chain. DC vaccine development focused on establishing the method for monocyte isolation and establishing Quality Control (QC) release and characterization assays to assess the final vaccine product.

\section{Results}

We found that monocytes from HIV-positive subjects can be isolated by elutriation. LIPO5-loaded DC vaccines cultured from the isolated monocytes expressed $61.5+$ $27.7 \%$ of CD $14+, 94.0+3.6 \%$ of HLA-DR+/CD $11 \mathrm{C}+, 94.8$ $+2.5 \%$ of $\mathrm{CD} 80+, 74.2+23.5 \%$ of CD83+, and $28.5+$ $14.9 \%$ of Langerin. There was a strong proliferative response in allogeneic $T$ cells cocultured with the LIPO5loaded DC vaccine, as seen in a mixed lymphocyte reaction assay. Furthermore, the vaccine was able to elicit an HIV antigen-specific response by autologous $\mathrm{T}$ cells, as measured by intracellular IFN- $\gamma$ staining. At least one peptide epitope response was induced per subject, in which the majority of the responses were CD8+ T cells and one was a CD4+ T cell response.

\section{Conclusion}

Collectively, these results paved the way for conducting a pilot DC vaccine clinical trial in HIV patients on HAART (BB-IND 13748). 